\section{Balloon Dilation of the Papilla Via a Forward- Viewing Endoscope: an Aid to Therapeutic Endo- scopic Retrograde Cholangiopancreatography in Patients with Billroth-II Gastrectomy}

Therapeutic endoscopic retrograde cholangiopancreatography (ERCP) in the presence of a Billroth II (B-II) partial gastrectomy is often difficult. We describe here a role for balloon dilation of the papilla in this context.

An 84-year-old man, who had previously undergone B-II gastrectomy, and had obstructive jaundice and common bile duct dilation on ultrasonography, was referred for ERCP. Having visualized the papilla and achieved selective cannulation of the common bile duct via a forward-viewing gastroscope (Olympus Q20), we showed the presence of a single, large, mobile stone. However, we could not cut the sphincter with a "B-II-type" 2.3-mm papillotome, despite apparently correct placement, within safe diathermy settings. We repeated cannulation via a gastroscope with a therapeutic channel (Olympus IT), passed a 10-mm biliary balloon catheter (Olbert catheter system, Meadox-Surgimed, Stenlose, Denmark) over a 0.035 -inch guide wire, and dilated the biliary sphincter (Figure 1). This did not allow stone extraction; and we intended to dilate the sphincter further and perform mechanical lithotripsy, but could not, because of patient restlessness and planned a further procedure. After the initial procedure, he had abdominal pain (maximum serum amylase $1566 \mathrm{U} / \mathrm{l}$ ), which settled without complication within 48 hours with conservative management. A repeat ERCP showed that the stone had passed spontaneously, and no further intervention was needed.

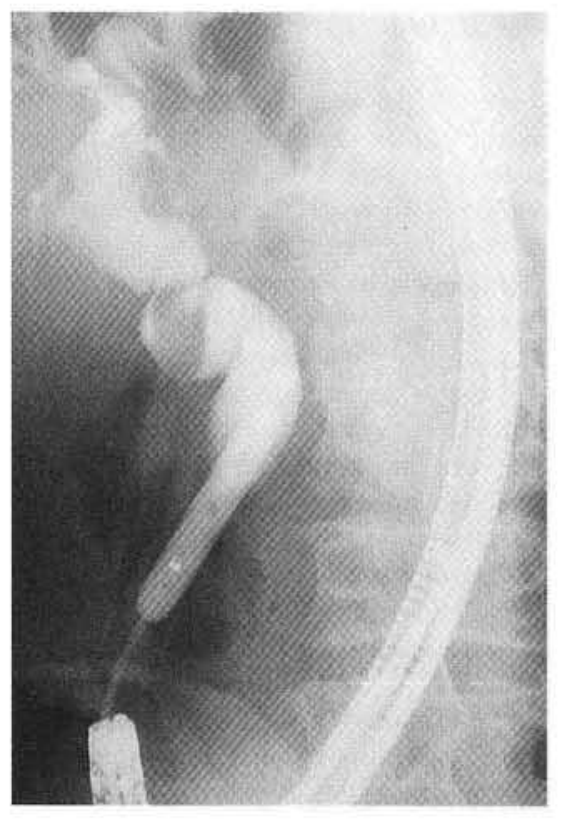

Figure 1: A balloon catheter being used to dilate the papilla via a forward-viewing gastroscope.

Balloon dilation of the papilla is a safe, effective technique that reduces the need for sphincterotomy in the management of bile duct stones $(1,2)$. A theoretical advantage is that it may preserve long-term sphincter function in young patients. Despite the availability of dedicated sigmoid loop sphincterotomes, therapeutic ERCP in the B-II setting remains technically difficult and often hazardous, although success has been reported with stent-guided needle-knife sphincterotomy (3). Via the forward-viewing endoscope, balloon dilation (with mechanical lithotripsy if needed) offers obvious advantages over sphincterotomy in the B-II context, which we have not seen described before, and which deserve further study. 
W. Dickey, S. Jacob, K. G. Porter

Dept, of Medicine, Queen's University of Belfast, Northern Ireland, United Kingdom

Dept. of Gastroenterology, Belfast City Hospital, Northern Ireland, United Kingdom

\section{References}

1. MacMathuna P, White P, Clarke E, Lennon J, Crowe J. Endoscopic sphincteroplasty: a novel and safe alternative to papillotomy in the management of bile duct stones. Gut 1994; 35: $127-9$.

2. Bergman JJGHM, Rauws EAJ, Tytgat GNJ, Huibregtse K. A prospective randomized trial comparing endoscopic sphincterotomy with endoscopic balloon dilation for removal of common bile duct stones: initial report. Gastrointest Endosc 1994; 40 (suppl): P99.
3. Meenan J, van Dullemen H, Tytgat GN, Huibregtse K. Endoprosthesis-guided needle-knife biliary sphincterotomy is efficient in cases of Billroth II gastrectomy. Gastrointest Endosc 1994; 40 (suppl): P29.

Corresponding Author

W. Dickey, M. D.

Dept. of Medicine

Institute of Clinical Science

Grosvenor Road

Belfast BT12 6BJ

United Kingdom

Fax: +44-1504-61 1218 